\title{
Graphene-family nanomaterials assembled with cobalt oxides and cobalt nanoparticles as hybrid supercapacitive electrodes and enzymeless glucose detection platforms - CORRIGENDUM
}

\author{
Sanju Gupta, Sara B. Carrizosa, Benjamin McDonald, Jacek Jasinski, and Nicholas Dimakis \\ doi: $10.1557 / j m r .2016 .484$, Published by Materials Research Society with Cambridge University \\ Press, 27 December 2016.
}

In Gupta et al. ${ }^{1}$, the author Nicholas Dimakis's first name was misspelled as "Nikolaos."

The authors regret this error, and the original has since been updated.

\section{REFERENCE}

1. S. Gupta, S.B. Carrizosa, B. McDonald, J. Jasinski, and N. Dimakis: Graphene-family nanomaterials assembled with cobalt oxides and cobalt nanoparticles as hybrid supercapacitive electrodes and enzymeless glucose detection platforms. J Mater. Res. 32(2), 301-322 (2017). doi: 10.1557/jmr.2016.484. 